\title{
Cryptophthalmos: surgical treatment of the congenital symblepharon variant
}

\author{
D J BRAZIER, S J HARDMAN-LEA, AND J R O COLLIN \\ From the Hospital for Sick Children, Great Ormond Street, London WC1 and Moorfields Eye Hospital, City \\ Road, London EC1.
}

SUMMARY A case of the congenital symblepharon variant of cryptophthalmos is reported. Surgical treatment is described. The ophthalmic features of cryptophthalmos and its systemic associations are reviewed.

The term cryptophthalmos was introduced by Zehender ${ }^{1}$ and $\mathrm{Manz}^{2}$ in 1872 when they described a child whose eyes were covered by continuous sheets of skin extending from forehead to cheeks. Emburger et al. ${ }^{3}$ attributed the earliest description to Saint-Hilaire in 1832. This paper reports the clinical features and early surgical management of the variant of cryptophthalmos to which François ${ }^{4}$ gave the name 'congenital symblepharon.'

\section{Case history}

A female child was born by spontaneous vaginal delivery at 40 weeks gestation to non-consanguineous parents. She was the first child of both parents. The baby was immediately noted to have a marked abnormality of the left upper eyelid involving absence of the lid margin and lashes, with adherence of the lid skin to the upper one-third of the cornea (Fig. 1 and 2). The upper lacrimal punctum was absent. The lower lid and fornix were normal and the punctum present. The lower two-thirds of the cornea and the remainder of the anterior segment appeared normal. The right eye and lids showed no abnormality.

Other abnormalities were also present. The left temporal region appeared depressed, and the left eyebrow was replaced by a downward sweep of the frontal hairline (Fig. 1). The ears were of a simple pattern, low-set, and had narrow external meati. The nose was dimpled at the tip and the left nostril notched. The frenulum of the tongue was short and respiration noisy owing to variable laryngeal stridor. There was syndactyly in both hands (Fig. 3), but in other respects the limbs appeared normal. No other

Correspondence to Mr D J Brazier, Department of Clinical Pharmacology, St Thomas's Hospital, London SE1 7EH. abnormalities were detected on examination of chest, abdomen, and external genitalia. Skull and chest radiographs were considered to be within normal limits.

The adhesion of the upper lid to the cornea was responsible for extensive corneal exposure, which

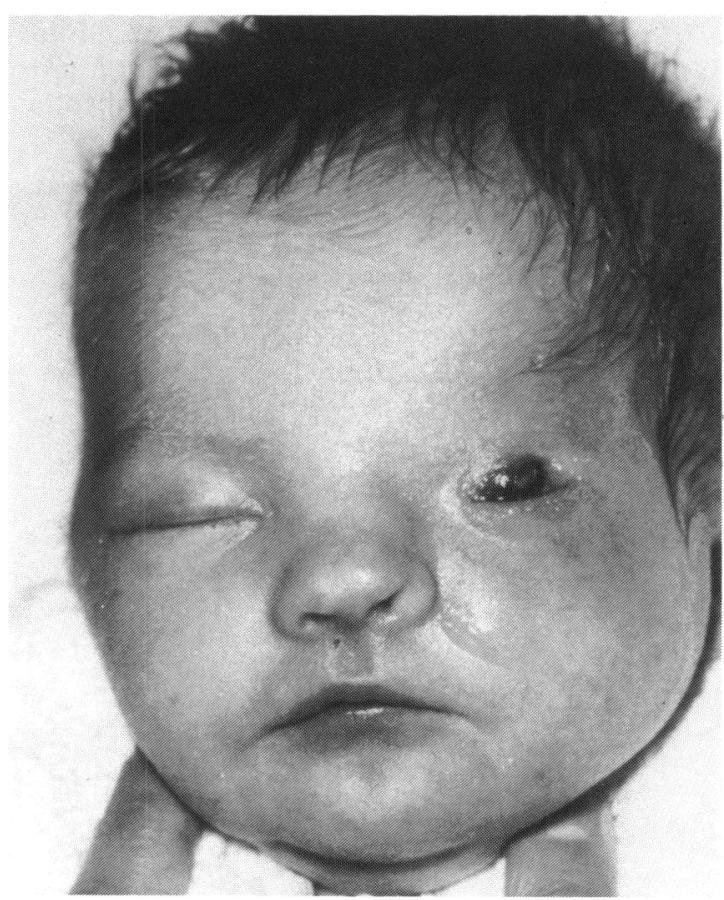

Fig. 1 Age 5 days. The left upper lid has no lashes or defined margin and is adherent to the underlying globe. The left eyebrow is replaced by a downward extension of the frontal hairline. 
Fig. 2 Age 5 days. The central corneal infiltrate and overlying epithelial defect are visible. The left nostril is notched.

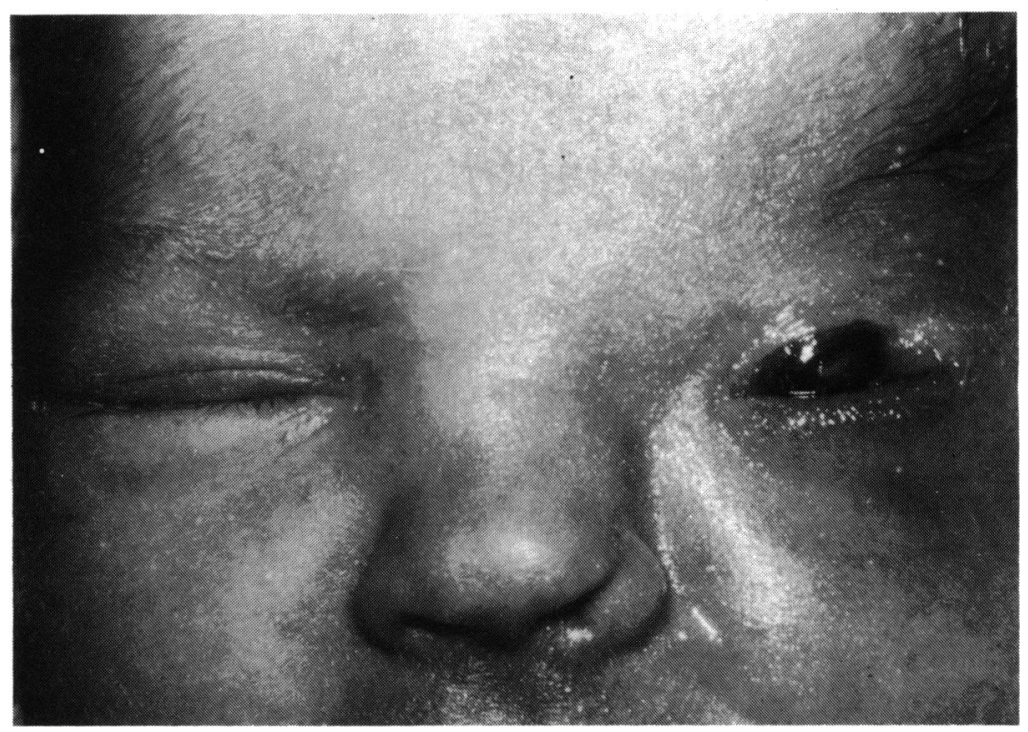

was initially treated conservatively by the hourly application of chloramphenicol eye ointment. During the following days, while a more detailed paediatric assessment was made, a corneal epithelial defect with increasing stromal infiltrate appeared in clear cornea adjacent to the margin of the upper lid skin. Surgical intervention was thought to be required to ensure corneal protection, and the child underwent a procedure involving a lid rotation flap, as described by Mustardé, ${ }^{5}$ when six days old.

Examination under anaesthesia confirmed the preoperative findings on the left and that the right eye,

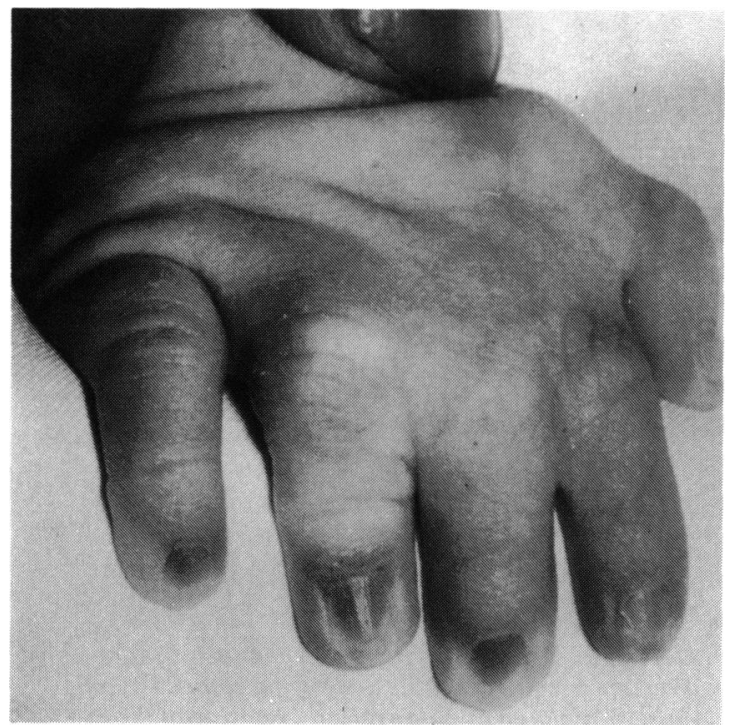

Fig. 3 Syndactyly, right hand. The left hand was similar. including the fundus, was normal. A skin incision was made adjacent to the skin edge where the left upper lid met cornea and conjunctiva (Fig. 4a). The skin was freed from grey upper cornea and adjacent sclera. A rudimentary levator palpebrae superioris muscle and normal superior rectus muscle were identified. A full thickness incision was made in the lower lid starting lateral to the punctum, sweeping down in an arc to the inferior extremity of the lower fornix and back up almost to the lid margin at its midpoint (Fig. 4a). Care was taken to preserve the marginal artery of the lid. The medial end of the lower lid was then rotated through $180^{\circ}$ round the hinge, consisting of full thickness tarsus and the marginal vessels, to produce a small laterally placed palpebral aperture (Fig. 4b). The conjunctiva of the new upper lid was attached to the superior rectus insertion and the levator aponeurosis sutured to the tarsus of the rotated lid segment to provide some mobility. Residual edges of conjunctiva and skin were closed with collagen sutures (Fig. 4c) Postoperative recovery was uncomplicated, and the wounds healed satisfactorily (Fig. 5).

Three weeks later the bridge of tarsus linking upper and lower lids was divided and the lid margins resutured. The corneal epithelium had healed, but the central and superior stromal opacity persisted. There was some movement of the reconstructed upper lid, and, although the lids remained slightly open during sleep, corneal protection was much improved. No further corneal ulceration developed with a regimen of chloramphenicol eye ointment six hourly.

During this period the child had been fully assessed. Chromosome studies were normal. Micro- 

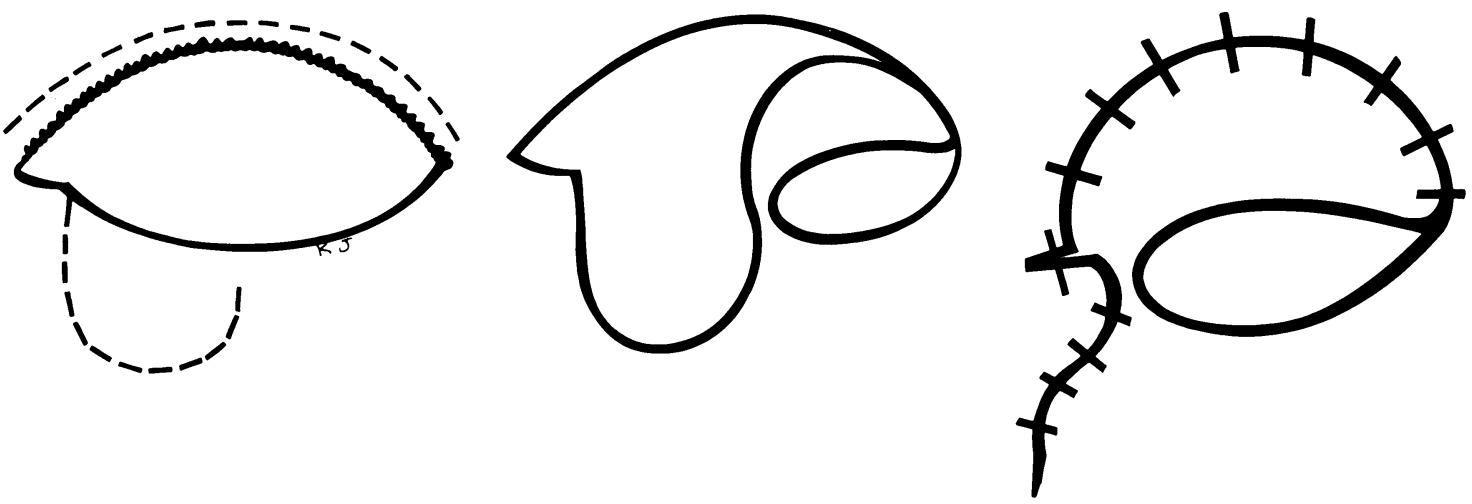

Fig. 4 Lid rotation flap. (a) Rotation incisions. (b) Rotation of medial end of lower lid. (c) Skin edges sutured.

laryngoscopy revealed that the arytenoids were fixed together in the midline posteriorly, giving rise to a narrow glottic slit. No subglottic stenosis of the trachea was identified. Renal ultrasound showed the kidneys to be present but small (right $3.4 \mathrm{~cm}$, left 3.5 $\mathrm{cm}$, expected size $4.0 \mathrm{~cm}$ ). Corticomedullary distinction was normal, and no cysts were present. Blood urea and creatinine levels were normal. A micturating cystourethrogram showed no abnormality of ureters, bladder, or urethra. Tight anal stenosis required dilatation under general anaesthesia.

When the baby was examined at the age of 4 months the left lids were soundly healed (Fig. 6). Some upper lid symblepharon persisted, but the cornea was stable and ocular lubricants were not required. Visual attention with the right eye was normal, and closure of the left eye was observed when this eye alone was exposed to bright light. A haemangioma of the upper lip had developed and was causing minor feeding problems (Fig. 7).

Flash visually evoked responses and an electroretinogram, without sedation or anaesthesia, showed cortical responses of normal amplitude and latency and a well defined retinal response from both eyes.

The child remains under regular review and will almost certainly require further division of upper lid symblepharon with mucous membrane grafting when older.

\section{Discussion}

Since its description by Zehender and Manz most information regarding cryptophthalmos has been recorded in the form of case reports. The most comprehensive review of the ocular condition and its recognised systemic associations is that published

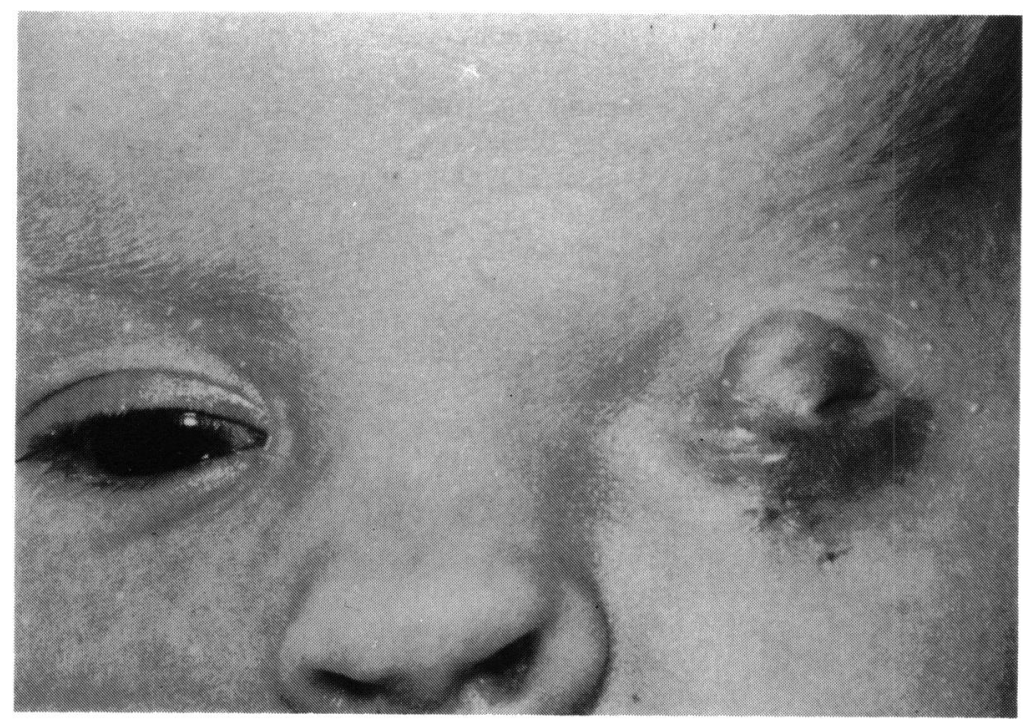

Fig. 5 Age 1 month (27 days after rotation flap). 
Fig. 6 Age 4 months, three bridge between left lids. Inferior cornea healed. months after division of tarsal

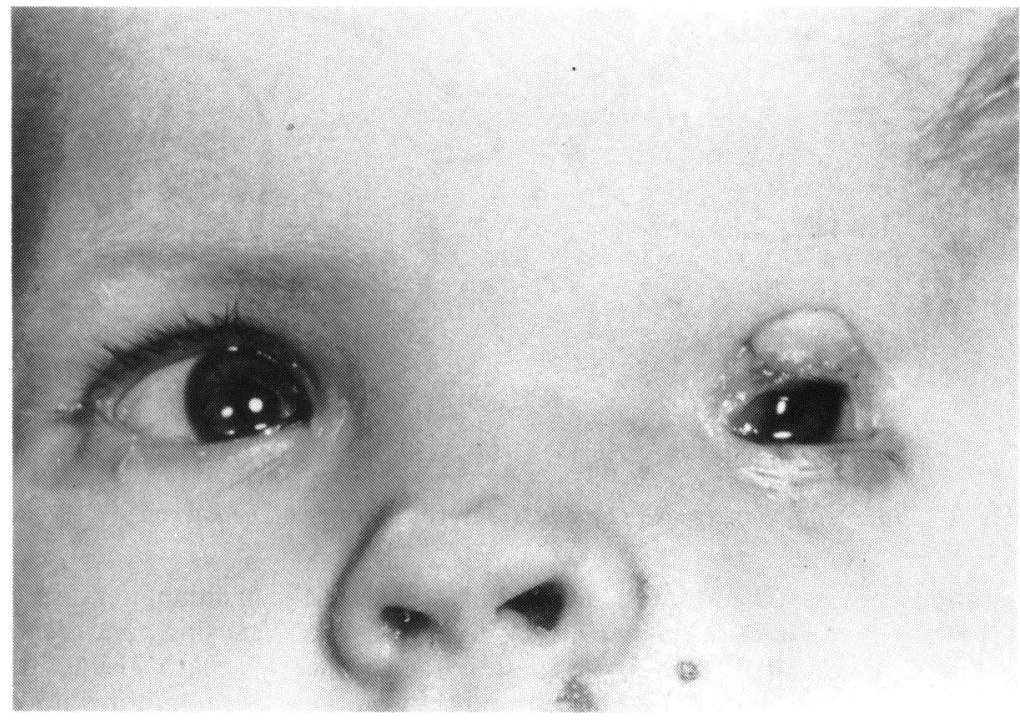

1. Complete (typical) cryptophthalmos. The lids by François. ${ }^{4}$ Cryptophthalmos in association with these specific systemic features is called, by various authors, cryptopthalmos syndrome, François syndrome, or Fraser syndrome. ${ }^{67}$ François reviewed 41 cases from the literature and added two new ones. $\mathrm{He}$ divided the ophthalmic signs into three groups:

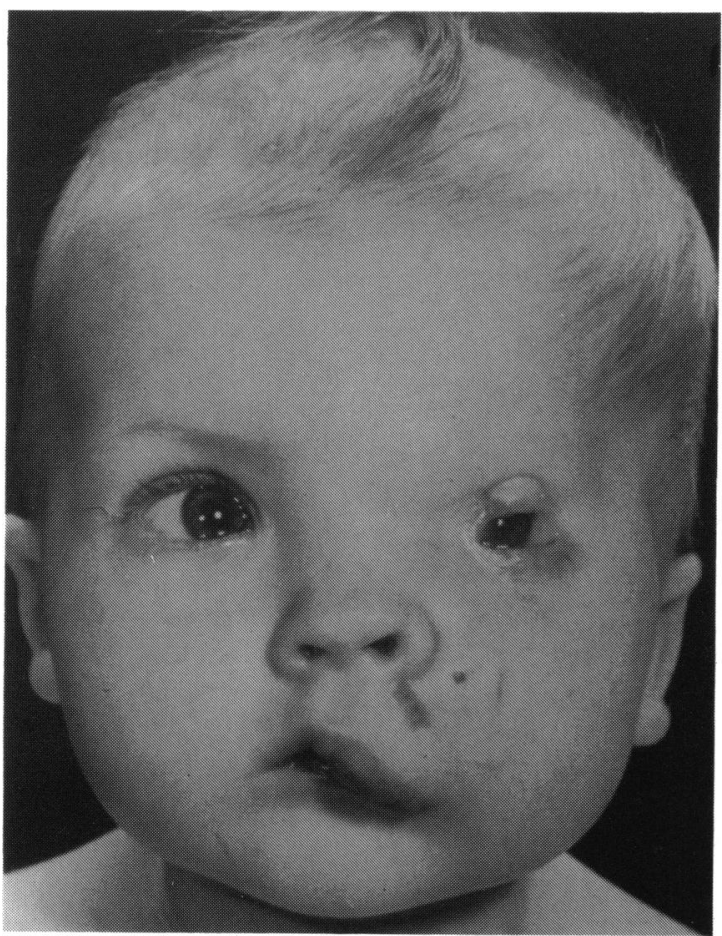

Fig. 7 Age 4 months. Haemangioma of upper lip present. are replaced by a sheet of skin running from forehead to cheek with absence or poor development of the eyebrow. No lashes or gland structures can be identified. The covered globe gives rise to an elevation in the overlying skin which moves when eye movements occur. The skin is adherent to the underlying cornea and there is no conjunctival sac. Microphthalmos is usual.

2. Incomplete (atypical) cryptophthalmos. Rudimentary lids are present, with a small conjunctival sac placed laterally. The palpebral aperture is about one-third of normal length. The globe is usually small and almost completely covered by skin.

3. Abortive form or congenital symblepharon. The upper lid, without a defined margin, covers and no punctum and there is no upper conjunctival fornix. The free part of the cornea may be keratinised and opaque. The globe is usually of normal size but may be small.

The ophthalmic features of the reported case therefore appear to be typical of the congenital symblepharon variant of cryptophthalmos and in almost all respects identical to those of cases pubSugar. ${ }^{9}$ These three patients were considerably older when reported, being 3,12 , and 35 years respectively. While the uncovered portion of the cornea in our case was clear at birth, it appears that keratinisation and opacity of the cornea may occur before birth. Emburger et al. ${ }^{3}$ reported a post-mortem study of a stillborn infant of 7 months gestation with multiple malformations including left congenital symblepharon. Microscopically this cornea proved to be adheres to up to $75 \%$ of the upper cornea. The lid has lished by François (observation II), ${ }^{4} \mathrm{Key},{ }^{\circ}$ and 
vascularised and covered with partially keratinised stratified squamous epithelium. In the cases of François, Key and Sugar the inferior extremity of the cornea appears to be relatively clear. This may be explained by maintenance of the tear film and protection by the lower lid.

Previous detailed reports of congenital symblepharon ${ }^{4.10}$ do not include accounts of lid surgery designed to protect the exposed cornea. An account of surgical exploration in complete cryptophthalmos is provided by Gupta and Saxena," gical treatment of incomplete cryptophthalmos is described by Waring and Shields. ${ }^{12}$ The latter authors extended the small palpebral aperture medially by incision and dissection of the skin from the underlying globe. A conformer was placed to maintain the fornices. No details of follow-up were given.

The systemic associations of cryptophthalmos have been reviewed by various authors including François ${ }^{4}$ and Ide and Wollschlaeger. ${ }^{13}$ These associated anomalies are known to include abnormalities of head shape, nose and ears, meningoencephalocele, hare lip and cleft palate, syndactyly, genital anomalies, and a miscellaneous group of defects including atresia of larynx, kidneys, bladder and anus, and umbilical hernia.

It seems likely that complete cryptophthalmos arises in the embryo because of total failure of lid fold development. ${ }^{12+14}$ The ectoderm overlying the cornea is converted into skin and no conjunctival sac formed. The congenital symblepharon variant may result from failure of the portion of lid fold derived from the frontonasal process while the portion derived from the maxillary process develops normally. This would explain the abnormal upper lid and normal lower lid. Perhaps subnormal development of the whole lid fold gives rise to the incomplete form of cryptophthalmos.

There is considerable evidence to suggest an autosomal recessive mode of inheritance for cryptophthalmos syndrome, and there are a number of reports of multiple cases occurring in some fami- lies. ${ }^{4615}$ Genetic counselling of couples with affected children seems advisable.

We thank Mr R Butler for referring the patients and our many colleagues at Great Ormond Street who helped with her management, particularly Dr J Burn of the Department of Medical Genetics. We also thank Karen Johnstone for drawing the diagrams and all the members of the departments of medical illustration at Great Ormond Street and Moorfields who took and prepared the photographs. We are grateful to $\mathrm{Mr} \mathrm{T} \mathbf{J}$ Ffytche for his help with translation of the German papers.

\section{References}

1 Zehender W. Eine Missegeburt mit hautüberwachsenen Augen oder Kryptophthalmos. Klin Monatsbl Augenheilkd 1872; 10: 224-34.

2 Manz. Anatomische Beschreibung det Augen. Klin Monatsbl Augenheilkd 1872; 10: 234-49.

3 Emburger JM, Pincemin D, Taib J, Caderas de Kerleau J. Etude anatomique d'une observation de cryptophtalmie familiale. $J$ Genet Hum 1976; 24 suppl: 23-9.

4 François J. Syndrome malformatif avec cryptophtalmie. Acta Genet Med Gemellol (Roma) 1969; 18: 18-50.

5 Mustardé JC. Repair and reconstruction in the orbital region. London: Churchill Livingstone, 1980: 130-43.

6 Fraser CR. Our genetic load. A review of some aspects of genetic variation. Ann Hum Genet 1962; 25: 387-415.

7 Burn J, Marwood RP. Fraser syndrome presenting as bilateral renal agenesis in three sibs. $J$ Med Genet 1982; 19: 360-1.

8 Key SN. Report of a case of cryptophthalmia. Am J Ophthalmol 1920; 3: 684-5.

9 Sugar HS. The cryptophthalmos-syndactyly syndrome. Am J Ophthalmol 1968; 66: 897-9.

10 Blessig E. Fall einer seltenen Missbildung der Augen: Symblepharon totale Congen. palp. sup. oc. dextri, Ankyloblepharon totale Congenitum, Kryptophthalmos oc. sinistri. Klin Monatsbl Augenheilkd 1900; 38: 652-62.

11 Gupta SP, Saxena RC. Cryptophthalmos. BrJ Ophthalmol 1962; 46: $629-32$

12 Waring GO, Shields JA. Partial unilateral cryptophthalmos with syndactyly, brachycephaly and renal anomalies. Am J Ophthalmol 1975; 79: 437-40.

13 Ide $\mathrm{CH}$, Wollschlaeger PB. Multiple congenital abnormalities associated with cryptophthalmia. Arch Ophthalmol 1969; 81: 640-4.

14 Duke-Elder S. In: Duke-Elder S, ed. System of ophthalmology. London: Kimpton, 1964; 3 (2): 829.

15 Lurie IW. Cherstvoy ED. Renal agensis as a diagnostic feature of the cryptophthalmos-syndactyly syndrome. Clin Genet 1984; 25: $528-32$.

Accepted for publication 10 September 1985 